\title{
Ocorrência do ácaro fitófago Catarhinus tricholaenae Keifer (Acari: Diptilomiopidae) em cultivares de milho Bt
}

\author{
Occurrence of the phytophagous mite Catarhinus tricholaenae Keifer (Acari: Diptilomiopidae) on Bt \\ corn cultivars
}

\author{
Marcos Antônio Matiello Fadini ${ }^{{ }^{*}}$ Octavio Gabryel Araujo" Simone Martins Mendes ${ }^{\text {II }}$ \\ Cidália Gabriela Santos Marinho'
}

\section{RESUMO}

O objetivo deste trabalho foi avaliar a ocorrência do microácaro-da-face-inferior-das-folhas-de-milho Catarhinus tricholaenae Keifer (Acari: Diptilomiopidae) em cultivares transgênicas de milho, contendo as proteínas Cry1F e Cry 1 A(b) e milho não Bt. Durante o período de junho de 2010 a janeiro de 2011, foram coletadas, quinzenalmente, cinco amostras aleatórias de quatro folhas em talhões de milho Bt, contendo a proteína Cry $1 F$ e Cry 1 A(b), e de milho não Bt em áreas experimentais da Embrapa Milho e Sorgo, em Sete Lagoas, MG. As amostras de folhas foram vistoriadas por 15 minutos na região da nervura central, em busca de adultos de $\boldsymbol{C}$. tricholaenae. Foram registrados 2.930 indivíduos de $\boldsymbol{C}$. tricholaenae, sendo que 1.114 no milho Bt Cry 1F, 753 em Cry 1 A(b) e 1063 indivíduos em folhas das cultivares não Bt. As maiores abundâncias populacionais médias ocorreram nos meses de novembro e dezembro. Os fatores estágio fenológico das plantas e precipitação afetaram positivamente a abundância de C. tricholaenae. A abundância média do período de coleta de C. tricholaenae foi reduzida pela cultivar de milho contendo a proteína Cry $1 \mathrm{~A}(\mathrm{~b})$. Esse é o primeiro registro de ácaros sobre cultivares de milho transgênico no Brasil.

Palavras-chave: plantas geneticamente modificadas, proteínas Cry, Diptilomiopidae.

\section{ABSTRACT}

The objective of this study was to evaluate the occurrence of "microácaro-da-face-inferior-das-folhas-demilho” Catarhinus tricholaenae Keifer (Acari: Diptilomiopidae) on transgenic cultivars of corn containing proteins Cry1F and Cry 1 A (b) and non-Bt corn. During the period from June 2010 to January 2011 were collected, every two weeks, five random samples of four leaves in plots of Bt corn containing the protein Cry $1 F$ and Cry $1 \mathrm{~A}(\mathrm{~b})$ and non-Bt corn in the experimental area of Embrapa Corn and Sorghum, Sete Lagoas, MG. The leaf samples were examined for 15 minutes in the central region of leaf in search of adult $C$. tricholaenae. We recorded 2930 individuals of $\boldsymbol{C}$. tricholaenae, 1114 on Bt Cry 1F, 752 on Cry 1 A (b) and 1063 individuals on leaves of nonBt cultivars. The highest average population abundances occurred in the months of November and December. Factors of plant phenological stage and rainfall positively affected the abundance of $\mathrm{C}$. tricholaenae. The average abundance of the collection period of $\boldsymbol{C}$. tricholaenae was reduced by cultivar corn containing Cry 1 A (b) protein. This is the first report of mites on the cultivars of transgenic corn in Brazil.

Key words: genetically modified plant, Cry protein, Diptilomiopidae.

\section{INTRODUÇÃO}

Os ácaros fitófagos são pragas importantes em várias culturas agrícolas, pois provocam injúrias que resultam em perdas econômicas. Apesar disso, a literatura técnica que recomenda estratégias de manejo de pragas na cultura do milho (Zea mays L.) no Brasil não faz referência a registros de populações de ácaros que alcançaram o status de praga (FADINI et al., 2010). Em outros países, como os Estados Unidos e o México, existem registros de espécies de ácaros como importantes pragas do milho (BARRON \& MARGOLIES, 1991). Nos Estados Unidos, a espécie Oligonychus pratensis (Banks) (Acari: Tetranychidae) é considerada uma importante praga do milho e do sorgo no oeste americano. Essa espécie infesta o milho no

IUniversidade Federal de São João Del-Rei (UFSJ), CP 56, 35701-970, Sete Lagoas, MG, Brasil. E-mail: fadini@ufsj.edu.br.

*Autor para correspondência.

"Embrapa Milho e Sorgo, Sete Lagoas, MG, Brasil. 
início da primavera e, quando as plantas se encontram em senescência, migram para culturas adjacentes, como o trigo (BARRON \& MARGOLIES, 1991). No México, os gêneros Tetranychus e Oligonychus (Acari: Tetranychidae) estão entre os que possuem espécies importantes como pragas do milho (BARRON \& MARGOLIES, 1991).

MORAES \& FLECHTMANN (2008) registraram as espécies microácaro-da-face-inferiordas-folhas-de-milho Catarhinus tricholaenae Keifer (Acari: Diptilomiopidae); microácaro-de-ambas-asfaces-das-folhas-de-milho Aceria zeala Keifer (Acari: Eriophyidae); ácaro-rajado Tetranychus urticae Koch; ácaro-verde Oligonychus zeae (McGregor) (Acari: Tetranychidae); e Aceria tosichella Keifer (Acari: Eriophyidae) como ácaros que infestam plantas de milho. Em recentes levantamentos de espécies de ácaros realizados em cultivos de milho Bt na Embrapa Milho e Sorgo, Sete Lagoas, MG, têm-se registrado as espécies C. tricholaenae e A. zeala (FADINI et al. 2010).

Apesar de apresentarem pouca importância como pragas do milho no Brasil, os ácaros podem ser organismos indicadores de ocasionais efeitos de cultivares transgênicas sobre organismos não alvo na comunidade de artrópodes. No caso do milho, através de técnicas de biologia avançada, um gene da bactéria Bacillus thuringiensis Berliner (1911) foi introduzido em plantas, dando origem ao milho $B$ t, conferindo diferentes padrões de resistência às espécies de lepidópteros-praga (WAQUIL et al., 2002). Os genes codificadores da proteína $\mathrm{Bt}$ (denominados genes cry ou genes $b t$ ), introduzidos na planta, têm ação efetiva no controle de lepidópteros. Trabalhos têm avaliado o efeito de plantas geneticamente modificadas (GM) sobre organismos não alvos. Entretanto, são poucos os trabalhos que visam a avaliar o efeito de plantas de milho GM, como o milho Bt, tendo os ácaros como organismos não alvo. OBRIST et al. (2006) estudaram a eficiência de predação do ácaro predador Neoseiulus (=Amblyseius) cucumeris Oudemans (Acari: Phytoseiidae) quando alimentado com T. urticae criado sobre o milho Bt (Bt 11), que expressa a toxina Cry1A(b). Os resultados daquele trabalho indicaram que o ácaro predador $\boldsymbol{N}$. cucumeris não é sensível à toxina Cry1A(b), contida no corpo de $\boldsymbol{T}$. urticae. O mesmo resultado foi encontrado quando o ácaro predador foi alimentado com pólen do milho Bt. Estudos dessa natureza são importantes para avaliar os efeitos de plantas GM sobre inimigos naturais e artrópodes-pragas de importância econômica secundária ou sem importância econômica. LI \& ROMEIS (2010) avaliaram o efeito de cultivares de milho que expressavam a proteína inseticida Cry3Bb1 sobre parâmetros da história de vida de T. urticae e verificaram que o desenvolvimento da fase imatura e a reprodução de $\boldsymbol{T}$. urticae não foram afetados pela alimentação sobre plantas GM. Tais resultados são similares aos encontrados quando se avaliou a biologia de T. urticae sobre outras culturas GM, a exemplo do algodão (ESTEVES FILHO et al., 2010).

O objetivo do trabalho foi avaliar a ocorrência do microácaro-da-face-inferior-das-folhasde-milho $\boldsymbol{C}$. tricholaenae em cultivares transgênicas de milho contendo as proteínas Cry1F e Cry 1 A(b). Testou-se a hipótese nula de que a defesa da planta, conferida pelas toxinas do milho $\mathrm{Bt}$, não afetaria a população do ácaro fitófago.

\section{MATERIAL E MÉTODOS}

Durante o período de 02 de junho de 2010 a 06 de janeiro de 2011, foram coletadas, quinzenalmente, cinco amostras aleatórias de quatro folhas por talhão $\left(100 \mathrm{~m}^{2}\right)$ de cultivares de milho não Bt (30F35) e milhos $B t$ e os respectivos isogênicos contendo a proteína Cry 1F (30F35 Hx) e Cry 1 A(b) (30F35 YG) em área experimental da Embrapa Milho e Sorgo, em Sete Lagoas, Minas Gerais (19²8' latitude sul e longitude 44¹5’08" W GrW).

O material foi acondicionado individualmente em saco de papel e levado ao laboratório para triagem sob microscópio estereoscópico. Cada amostra de folhas foi triada individualmente por 15 minutos em busca de ácaros fitófagos na região da nervura central da face abaxial da folha, onde os ácaros são encontrados com maior frequência. Esse procedimento padronizou o esforço amostral por amostra das folhas. Os espécimes encontrados foram montados em lâmina com meio de Hoyer (MORAES \& FLECHTMANN, 2008) e as melhores montagens foram enviadas para confirmação da identificação taxonômica por especialistas para a Escola Superior de Agricultura "Luiz de Queiroz" (ESALQ). Lâminas com espécimes de $\boldsymbol{C}$. tricholaenae montados encontram-se armazenadas no Laboratório de Entomologia Agrícola da Universidade Federal de São João del-Rei, campus Sete Lagoas. Avaliaram-se a ocorrência e a dinâmica populacional dos indivíduos adultos móveis de $\boldsymbol{C}$. tricholaenae sobre as três cultivares de milho. Os dados meteorológicos de temperatura e de precipitação do período de coleta foram fornecidos pela estação meteorológica da Embrapa Milho e Sorgo.

O número de ácaros $\boldsymbol{C}$. tricholaenae por amostra foi transformado em $\log (\mathrm{x}+1)$ para homogeneizar as variâncias. Utilizou-se o comando lm (Linear Model) (CRAWLEY, 2007), tendo como variável 
dependente (y) o número de ácaros $\boldsymbol{C}$. tricholaenae coletado e, como variáveis independentes $(x$ 's), a cultivar, o estágio fenológico da planta (=tempo após o plantio), a temperatura média e a precipitação média dos quatro dias anteriores às coletas. Os testes foram realizados com nível de significância de 5\%. Foi utilizado o programa estatístico R (R Development Core Team, 2006) para a análise dos dados.

\section{RESULTADOS E DISCUSSÃO}

Foram coletados 2.930 indivíduos adultos de $\boldsymbol{C}$. tricholaenae, sendo que 1063 em folhas de cultivares não $B t, 1.114$ em cultivar $B t$ Cry1F e 753 em milho Bt Cry1A(b). As maiores abundâncias populacionais médias ocorreram nos meses de novembro (45,0 em não Bt; 98,6 em Cry 1F; 49,6 em Cry 1 A(b)) e dezembro (72,6 em não Bt; 49,0 em Cry 1F; 39,0 em Cry 1 A(b)) (Figura 1A). As abundâncias populacionais médias de $\boldsymbol{C}$. tricholaenae, durante todo o período de coleta, foram 13,3; 13,9 e 9,4 para cultivares não $B t$, e contendo as proteínas Cry 1F e Cry 1 A(b), respectivamente.

A variável cultivar, proteína Cry 1 A(b), teve afeito no número de ácaros $\boldsymbol{C}$. tricholaenae (g.l.=2; $\mathrm{F}=4,23 ; \mathrm{P}<0,001$ ). As médias do número de ácaros em milho não $B t$ e expressando a proteína Cry $1 \mathrm{~F}$ não diferiram entre si, entretanto, diferiram da média daquele cultivar expressando Cry $1 \mathrm{~A}(\mathrm{~b})$, na qual houve redução do número de ácaros.

A dinâmica populacional de $\boldsymbol{C}$. tricholaenae foi afetada pela precipitação pluviométrica (g.l.=1; $\mathrm{F}=74,52 ; \mathrm{P}<0,001$ ). Contrariamente ao que se esperava, foi observada correlação positiva entre precipitação e abundância de $\boldsymbol{C}$. tricholaenae, ou seja, o número de ácaros aumentou com a quantidade de chuvas. Embora a temperatura não tenha afetado a abundância de $\boldsymbol{C}$. tricholaenae (g.l. $=1 ; \mathrm{F}=0,23 ; \mathrm{p}=0,64$ ), a interação temperatura:precipitação foi significativa (g.l.=1; $\mathrm{F}=26,87 ; \mathrm{P}<0,001$ ).

A fenologia da planta, representada pela variável tempo e incorporada às análises, afetou a

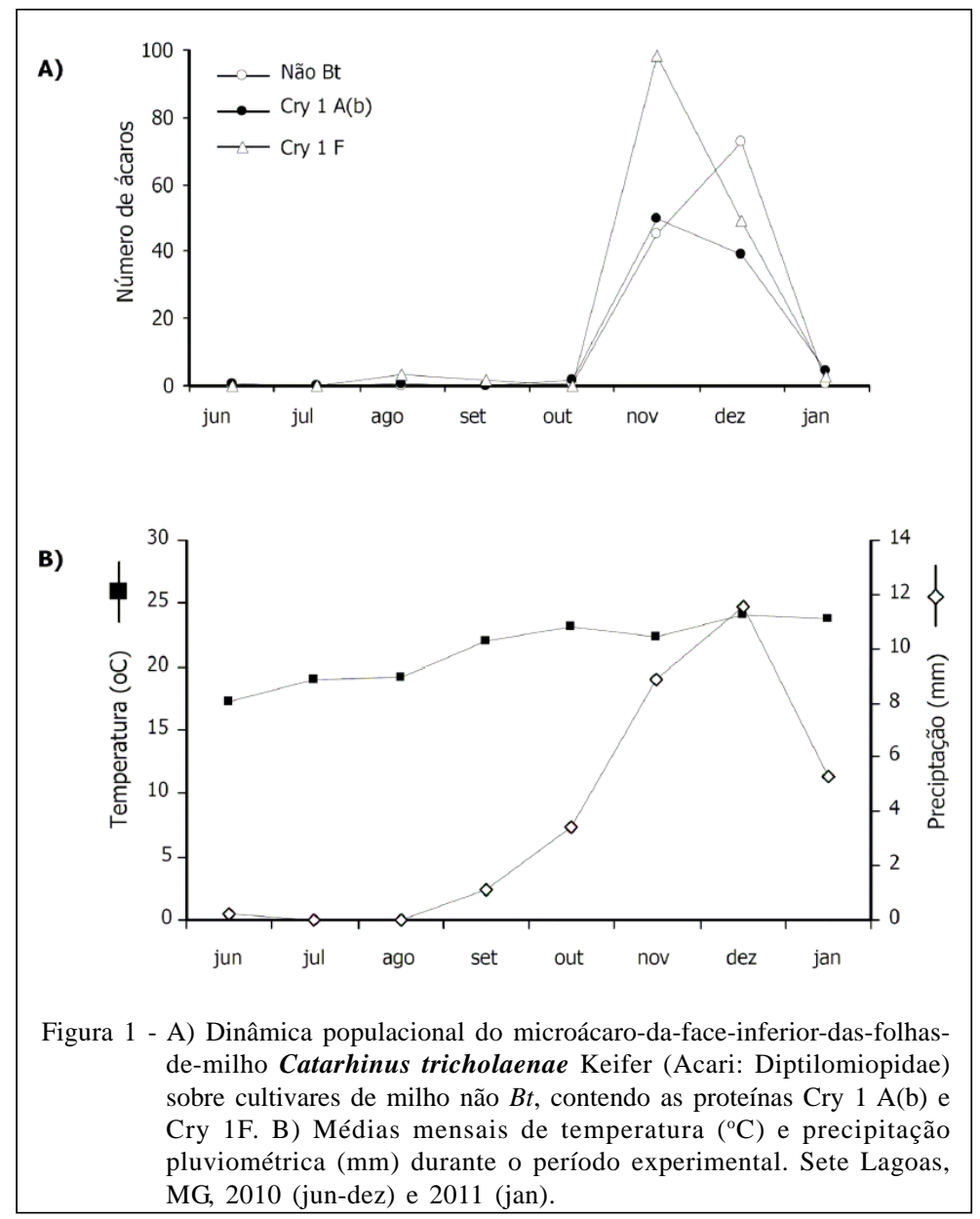

Ciência Rural, v.42, n.9, set, 2012. 
abundância de $\boldsymbol{C}$. tricholaenae (g.l.=1; F=1.236,59; $\mathrm{P}<0,001)$. Tal correlação positiva é corroborada pelo fato de as plantas maiores suportarem maior número de ácaros até o estágio de senescência, no qual a qualidade dos recursos alimentares para os ácaros é reduzida. As cultivares de milho afetaram a dinâmica populacional de $\boldsymbol{C}$. tricholaenae. As médias populacionais de $\boldsymbol{C}$. tricholaenae na cultivar que expressa a proteína Cry 1 A(b) foram menores quando comparadas com as demais cultivares avaliadas. Tal resultado foi inesperado, pois, devido à especificidade das toxinas $B t$ serem de defesa contra lagartas, não se esperava efeito sobre a abundância de ácaros.

São escassos os relatos de efeitos de plantas GM sobre ácaros. Foram estudados os efeitos de inibidores de protease em soja e de algodão geneticamente modificado sobre a espécie do ácaro de solo Scheloribates praeincisus (Acari: Oribatida). Os resultados mostraram que as referidas defesas das plantas não afetaram os parâmetros biológicos avaliados para a espécie $\boldsymbol{S}$. praeincisus, sendo inócuo para esse organismo não alvo (OLIVEIRA et al., 2007; SIMÕES et al., 2008).

O presente relato é o primeiro estudo sobre ácaros fitófagos em cultivares de milho transgênico no Brasil. O estudo do efeito desse tipo de defesa de plantas é necessário para se avaliar a abundância e a diversidade de espécies não alvo em agroecossistemas. Sendo a tecnologia de milho $\mathrm{Bt}$ direcionada para o controle de lagartas e não para ácaros fitófagos, poderse-ia esperar, no campo, uma maior densidade populacional de ácaros fitófagos em lavouras de milho $B t$ do que em isogênico não Bt. Esse fato seria devido à ausência de lagartas que reduziriam a área foliar que seria colonizada por ácaros. Essa é uma hipótese que será testada através da avaliação da dinâmica populacional de ácaros no campo. O estudo dos efeitos de cultivares transgênicas sobre organismos não alvo pode fornecer informações de como esse tipo de defesa de plantas afeta teias alimentares de artrópodes (e.g. insetos e ácaros) em agroecossistemas.

\section{CONCLUSÃO}

A abundância do ácaro fitófago Catarhinus tricholaenae, em plantas de milho, é aumentada pela precipitação e fenologia da planta e reduzida pela proteína Cry $1 \mathrm{~A}(\mathrm{~b})$.

\section{AGRADECIMENTOS}

À Fundação de Amparo à Pesquisa do estado de Minas Gerais (FAPEMIG) e à Financiadora de Estudos e Projetos (FINEP), pelo auxílio financeiro na realização do trabalho. Ao projeto Lac
Biosafety. Aos Professores Carlos H.W. Flechtmann e Gilberto J. Moraes, pela identificação dos espécimes de ácaros coletados.

\section{REFERÊNCIAS}

BARRON, J.A.; MARGOLIES, D.C. Within-plant dispersal of banks grass mite (Acari: Tetranychidae) on corn. Journal of the Kansas Entomological Society, v.64, p.209-215, 1991.

CRAWLEY, M. The R book. West Sussex: Wiley, 2007. 942p.

ESTEVES FILHO, A.B. et al. Biologia comparada e comportamento de Tetranychus urticae Koch (Acari: Tetranychidae) e Phytoseiulus macropilis (Banks) (Acari: Phytoseiidae) em algodoeiro bollgard ${ }^{\mathrm{TM}}$ e Isolinha não-transgênica. Neotropical Entomology, v.39, p.338-344, 2010. Disponível em: <http://www.scielo.br/ scielo.ph p ? s c ript = sci_art text \& pid = S 1519 566X2010000300005\&nrm=iso\&tlng=pt $>$. Acesso em: 15 maio, 2012. doi.org/10.1590/S1519-566X2010000300005.

FADINI, M.A.M. et al. Os ácaros são pragas do milho no Brasil? Sete Lagoas: Embrapa Milho e Sorgo, 2010. 14p. (Série Documentos, 113).

LI, Y.; ROMEIS, J. et al. Bt maize expressing Cry3Bb1 does not harm the spider mite, Tetranychus urticae, or its ladybird beetle predator, Stethorus punctillum. Biological Control, v.53, p.337-344, 2010. Disponível em: <http:// w w w. sciencedirect.com/science/article / pi i / S1049964409003168>. Acesso em: 15 maio, 2012. doi.org/ 10.1016/j.biocontrol.2009.12.003.

MORAES, G.J.; FLECHTMANN, C.H.W. Manual de acarologia: acarologia básica e ácaros de plantas cultivadas no Brasil. Ribeirão Preto: Holos, 2008. 288p.

OBRIST, L.B. et al. Assessing the effects of Bt maize on the predatory mite Neoseiulus cucumeris. Experimental and Applied Acarology, v.38, p.125-139, 2006. Disponível em: <http://www.springerlink.com/content/5067p64244714t32/>. Acesso em: 15 maio, 2012. doi: 10.1007/s10493-006-0008-0.

OLIVEIRA, A.R. et al. Toxicological evaluation of genetically modiWed cotton (Bollgard ${ }^{\circledR}$ ) and Dipel ${ }^{\circledR}$ WP on the non-target soil mite Scheloribates praeincisus (Acari: Oribatida). Experimental and Applied Acarology, v.41, p.191-201, 2007. Disponível em: <http://www.springerlink.com/content/ qn1445523hh4w6j3/>. Acesso em: 15 maio, 2012. doi: 10.1007/s10493-007-9059-0.

R DEVELOPMENT CORE TEAM. R: a language and environment for statistical computing. Vienna: R Foundation for Statistical Computing, 2006.

SIMÕES, R.A. et al. Effects of soybean proteinase inhibitors on development of the soil mite Scheloribates praeincisus (Acari: Oribatida). Experimental and Applied Acarology, v.44, p.239-248, 2008. Disponível em: <http:// www.springerlink.com/content/b356g7011r772m95/>. Acesso em: 15 maio, 2012. doi: 10.1007/s10493-008-9139-9.

WAQUIL, J.M. et al. Resistência do milho (Zea mays L.) transgênico (Bt.) à lagarta-do-cartucho, Spodoptera frugiperda (Smith) (Lepidoptera: Noctuidae). Revista Brasileira de Milho e Sorgo, v.1, n.3, p.1-11, 2002. 